\title{
Integrin receptor subtype antagonism augments BNP-mediated cGMP generation in cultured human cardiac fibroblasts: evidence for particulate guanylate cyclase receptor and integrin receptor cross-talk
}

\author{
Brenda K Huntley* and John C Burnett Jr
}

Address: Cardiorenal Research Laboratory, Mayo Clinic and Mayo Clinic College of Medicine, Rochester, MN 55905 USA

Email: Brenda K Huntley* - huntley.brenda@mayo.edu

* Corresponding author

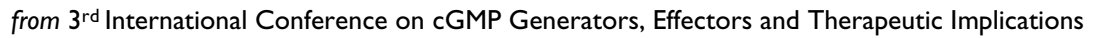

Dresden, Germany. 15-17 June 2007

Published: 25 July 2007

BMC Pharmacology 2007, 7(Suppl I):P30 doi:I0.II86/I47|-2210-7-SI-P30

This abstract is available from: http://www.biomedcentral.com//47I-22 I0/7/SI/P30

(c) 2007 Huntley and Burnett; licensee BioMed Central Ltd.

\section{Background}

BNP has emerged as a potent antifibrotic peptide inhibiting collagen production, augmenting matrix metalloproteinases, and suppressing proliferation in cardiac fibroblasts [1]. Particulate guanylate cyclase natriuretic peptide receptor A (NPR-A), to which BNP binds, shares structural (receptor dimerization and short unique cytoplasmic tails) and sequence (RGD motif binding DDX domains) similarities to integrin receptors and like integrins NPR-A may transduce signals from the extracellular matrix (ECM). Recently, we reported evidence for outside-inside signaling where by fibronectin (FN), an extracellular matrix protein, augments the increase in cGMP production by BNP in cultured human CFs plated on FN and is also augmented by a Mayo designed RGD peptide based upon an NPR-A sequence. It is reported that integrin receptor subtypes can regulate TGF beta binding to the TGB beta-receptor providing evidence for integrin TGF beta-receptor cross-talk. In view of these observations, we hypothesized that potential cross-talk may exist between NPR-A and integrin receptors in human CFs.

\section{Methods}

Human CFs were cultured as previously described. CFs were pre-incubated in HBSS containing Hepes, BSA, and IBMX for 10 minutes then treated with BNP $\left(10^{-6} \mathrm{M}\right)$ with or without antibodies to three integrin receptors that include antibodies to alpha-v-beta-3, beta- 8 and beta-3 integrin receptors. Cyclic GMP was measured as described previously.

\section{Results}

The alpha-v-beta-3 antibody had no effect on basal cGMP generation. In contrast, BNP markedly increased cGMP generation in CFs $(\mathrm{P}<0.05)$. Importantly, integrin alpha-v-beta3 antibody further augmented BNP stimulated cGMP generation $(120 \%, \mathrm{P}=.0295)$, as did integrin subunit antibody beta-8 $(145 \%, \mathrm{P}=0.0002)$, and integrin subunit antibody beta-3 (150\%, P = 0.02).

\section{Conclusion}

These studies provide new insight into the biology of particulate guanylate cyclase and integrin receptors in response to BNP stimulation in human CFs. Specifically, antibodies to integrin receptors augment BNP activation of CGMP in CFs. The mechanism of this augmentation remains undefined but may imply that integrin receptors interact directly with NPR-A to alter NPR-A sensitivity to BNP warranting further studies. The current observations suggest cross-talk between these two receptor types that play a key role in control of myocardial structure.

\section{References}

I. Huntley BK, Sandberg SM, Noser JA, Cataliotti A, Redfield MM, Matsuda Y, Burnett JC Jr: BNP-induced activation of CGMP in human cardiac fibroblasts: Interactions with fibronectin and natriuretic peptide receptors. J Cell Physiol 2006, 209:943-949. 